\title{
CONTOS DE MAGIA, SEDUÇÃO E MONSTRUOSIDADES NOS ROMANCES SATYRICON DE PETRÔNIO E METAMORPHOSEON DE APULEIO
}

\author{
Sandra Maria Gualberto Braga Bianchet* \\ Universidade Federal de Minas Gerais
}

\begin{abstract}
The aim of the present paper is analysing the strategy of embedding erotic and fantastic short narratives in Petronius' Satyricon and in Apuleius' Metamorphoseon. The function of those stories of magic and seduction in narrative composition, it is propposed, is a way of keeping the readers' attention to the central story, although it deviates from it directly.
\end{abstract}

KEYWORDS: latin novel; Satyricon; Apuleius; Petronius; fabula milesiana.

\section{Introdução}

e s obras de ficção em prosa Satyricon de Petrônio (séc. I d.C.) e Metamorphoseon ou Asinus aureus de Apuleio (séc. II d.C.) se estruturam de modo a incluir, na linha diegética central, uma série de histórias curtas, que envolvem a utilização de temas semelhantes: são episódios de cunho erótico e de feitiçaria e magia. Nesses passos, o foco narrativo é transferido do narrador autodiegético para uma personagem secundária, que assume a vez e a voz da narrativa. O narrador em primeira pessoa, que apresenta suas próprias aventuras, transforma-se, pois, em ouvinte das aventuras alheias, as quais ele reproduz como citação, mantendo a $1^{\text {a }}$ pessoa - ou seja, muda-se o "eu" da narrativa, abre-se espaço para o outro se pronunciar. Quanto aos episódios de cunho erótico, no Satyricon,

^sandra.bianchet@gmail.com 
têm-se as narrativas, feitas pelo poeta Eumolpo, de duas histórias de sedução: o garoto de Pérgamo (cap. 85 a 87) e a matrona de Éfeso (111 a 112), comumente analisadas como exemplares supérstites de fábulas milesianas; nas Metamorphoseon, concentram-se tais narrativas na sequência de histórias sobre adultério no livro nono, que, de alguma forma, encontram eco na narrativa da sedução da escrava Fótis pelo protagonista Lúcio nos livros 2 e 3.

Especificamente em relação a episódios de feitiçaria e magia, temse como tema principal a metamorfose, a transformação em outro ser, animalesco e/ ou monstruoso, por obra das artes mágicas.

A metamorfose é um tema que tem fascinado a mente humana há milênios. Ainda hoje pode ser considerada uma garantia de sucesso nas vendas das imagens de muitos dos "super-heróis" contemporâneos. No mundo antigo, o tema das metamorfoses faz parte do universo literário ocidental desde seu primeiro momento, com a Ilíada e a Odisseia de Homero. Às vezes são deuses que se transfiguram em humanos ou em animais, para transitar em terreno humano, ou humanos que se transformam em deuses, para poder transitar em terreno divino; outras vezes homens são transformados em animais, por artes mágicas de uma feiticeira. De fato, a inclusão desse tipo de argumentum, que remete ao novo, ao inaudito, ao monstruoso e que está presente em diversos autores da Antiguidade clássica, dentre os quais se destacam Homero e Ovídio, pode ser analisada como uma das principais estratégias para atrair a atenção do leitor/ ouvinte no romance latino.

A transfiguração no outro está presente no Satyricon mais especificamente no grupo de episódios da Cena Trimalchionis, quando o anfitrião convoca um de seus amigos a narrar uma história fantástica (conto do lobisomem) para, logo em seguida, ele próprio contar uma outra história maravilhosa (Sat. 61-63). Nas Metamorphoseon, a inserção de histórias breves configura-se como uma estratégia discursiva de uso mais recorrente; além disso, as histórias inseridas apresentam uma conexão mais direta com a narrativa principal da obra, já que o tema da magia é o motus da narrativa de Lúcio: literalmente, é o que coloca o narrador em movimento e desencadeia toda a série episódica de transfigurações por ele desenredada.

Os autores dos romances latinos lançam mão da estratégia de inserir "estórias" dentro da história, muitas vezes, informada ao leitor pelo narrador, que se mostra preocupado em justificar essa inserção, como, por exemplo, o faz a personagem Trimalquião, no grupo de episódios da Cena Trimalchionis (capítulos 27 a 78) em que os convivas são instados a dar sua contribuição aos espetáculos da ceia. Também nas 
Metamorphoseon a inserção de toda e qualquer história curta é justificada pelo protagonista. Dessa maneira, ao longo do Satyricon e das Metamorphoseon, paralelamente à narrativa das aventuras e desventuras do narrador Encólpio, inserem-se outras micronarrativas, com início-meio-fim. Nessas predomina ora o caráter fantástico, nas narrativas do jantar, como a do lobisomem ou a das bruxas, ora o caráter erótico-cômico, nas narrativas do poeta Eumolpo dos contos do garoto de Pérgamo (Sat. 85-87) e da Matrona de Éfeso (Sat. 111-112).

A narrativa fantástico-erótico-cômica se caracteriza, pois, como ficção da ficção, uma janela que se abre, talvez para que o leitor fique com a sensação de que o eixo narrativo central não é realmente ficcional. A estratégia de inserir narrativas periféricas parece dar maior credibilidade ao narrador, através de cujos olhos os leitores enxergam os eventos.

Outra justificativa apresentada pelo narrador é a de demarcar a passagem do tempo, como, por exemplo, no primeiro episódio das Metamorphoseon, em que ao leitor é apresentada uma narrativa fantástica - na verdade, a primeira metamorfose do livro. Trata-se de uma história contada por um dos companheiros de viagem do narrador: a história de um homem transformado em tartaruga. Essa história é ouvida por um terceiro personagem, que a recebe de modo incrédulo. Aqui nota-se uma contraposição entre ceticismo e credulidade $^{1}$ - o episódio narrado serve como advertência contra a propensão do narrador para acreditar muito facilmente no sobrenatural (Ego uero nihil impossibile arbitror. Met. I 20, 3).

A distração proporcionada pela narração do conto fantástico é recebida com entusiasmo pelo narrador, que já dá mostras de seu foco de interesse: a magia. $\mathrm{Na}$ verdade, o que move o narrador homodiegético das Metamorphoseon é a curiositas, que somada à credulitas, resulta em instabilidade.

Além da narrativa inserida no início do romance, desfilam pelas Metamorphoseon dezenas de outras histórias, que, em princípio, desviam a atenção do leitor do foco narrativo principal: a metamorfose intencional de Lúcio por efeito de magia. No entanto, por obra da fortuna caeca, o sonho da tão desejada metamorfose do protagonista em pássaro se transforma no pesadelo da metamorfose em asno! O adiamento do final da história - a metamorfose do burro em Lúcio - por meio das histórias tem seu ponto mais importante na narrativa do extenso conto do amor entre Cupido e Psyché (Amor e Alma), que ocupa parte do livro IV, todo o livro $\mathrm{V}$ e ainda parte do livro VI.

${ }^{1}$ Cf. Shumate, N. Apuleius' “Metamorphoses": the inserted tales. In: Hofman, H. (Org.). Latin fiction. The novel in context. London/ New York: Routledge, 2004. 


\section{Milesio sermone varias fabulas conseram (Met. I 1)}

Embora as fontes para os estudos das fábulas milesianas sejam escassas, o que não permite formar um corpus bem definido, a partir do qual se possa estabelecer com maior precisão suas características basilares, o pouco que se tem fornece informações consistentes e inequívocas acerca de sua temática e contexto de inserção: trata-se de narrativas curtas encaixadas em outras obras mais extensas, que apresentam um caráter imoral, mas irônico e divertido, expresso basicamente por temas pornográficos e sensacionalistas. ${ }^{2} \mathrm{O}$ forte caráter de abordagem de temas relacionados a sexo é destacado, por exemplo, por Ovídio, em sua Ars Amatoria (II 413-414), que se refere à obra de Aristides de Mileto, traduzida para o latim por Sisena, como uma produção literária que aborda "delitos milesianos":

\section{Iunxit Aristides Milesia crimina secum}

pulsus Aristides nec tamen urbe sua est. ${ }^{3}$

Ainda em outro passo da obra de Ovídio (Tristia II 443-444), destaca-se o conteúdo "imoral" das narrativas milesianas:

\section{Vertit Aristiden Sisenna, nec obfuit illi historiae turpis inseruisse iocos. ${ }^{4}$}

Outra caracterização importante das narrativas milesianas diz respeito a seu contexto de inserção. Via de regra, a introdução dessas narrativas indecentes e/ ou fabulosas ocorre após o jantar, por solicitação do anfitrião, espaço profícuo para tratar de amenidades, tempo para dedicar às nugae.

\footnotetext{
${ }^{2}$ Cf. Harrison, S. J. The Milesian tales and the Roman novel. In: Hofmann, H.; Zimmerman, M. (Org.). Groningen colloquia on the novel. Groningen: Egbert Forsten, 1998. Vol. IX, p. 61-74.

${ }^{3}$ Ovídio, Ars amatoria II 413-414: "Aristides associou-se aos delitos milesianos;/ não foi, contudo, expulso de sua cidade" (minha tradução).

${ }^{4}$ Ovídio, Tristia 443-444: "Sisena traduziu Aristides e não foi impedido de/ introduzir gracejos de história indecente" (minha tradução).
} 


\begin{abstract}
"Immo mi Thelyphron", Byrrhena inquit "et subsiste paulisper et more tuae urbanitatis fabulam illam tuam remetire, ut et filius meus iste Lucius lepidi sermonis tui perfruatur comitate".

Trimalchio ad Nicerotem respexit et: "Solebas, inquit, suavius esse in convictu; nescio quid nunc taces nec muttis. Oro te, sic felicem me videas, narra illud quod tibi usu uenit". ${ }^{6}$
\end{abstract}

A reação do conviva convocado a assumir a voz narrativa também segue um mesmo padrão. Num primeiro momento, o personagem hesita em aceitar o convite, hesitação justificada por receio de ser alvo de zombarias.

Vencida a resistência do personagem supra descrita, introduzemse as histórias de lobisomem (Sat. LXI-LXII) e de bruxas (Sat. LXIII) no Satyricon, durante a Cena Trimalchionis, e a história de Télifron, inserida no episódio das Metamorfoses que narra o jantar na casa de Birrena (Met. II 18-31). Também se destaca aqui a receptividade dessas histórias fantásticas por parte dos ouvintes, que tendem à incredulidade e a pôr em evidência seu caráter ficcional e anedótico.

Semelhantemente aos poemas no Satyricon, as fábulas milesianas, nas Metamorphoseon, cumprem a função de comentar o episódio central e, assim como o narrador homodiegético burro assume as narrativas das histórias, também o narrador homodiegético Encólpio assume a função de inserir poemas.

\title{
2 A inserção de histórias curtas no Satyricon e nas Metamorphoseon: narrationibus fabulisque auocare
}

O principal objetivo de inserir histórias no Satyricon e nas Metamorphoseon, declarado explicitamente pelos narradores, é o de mera fruição. São histórias introduzidas para mirari (Met. I 1, 2), laetari (Met. I 1, 6), auocare (Met. IV 27, 8), perfrui (Met. II 20, 7). Outro elemento textual que corrobora o caráter de amenidades das histórias inseridas é o adjetivo que as qualifica: as fabulae, outras vezes referidas como sermones ou narrationes,

\footnotetext{
${ }^{5}$ Metamorphoseon II 20, 7: Espera, meu caro Télifron, fica um pouco mais e, com a tua conhecida cortesia, conta-nos de novo essa aventura, a fim de que também esse meu filho, Lúcio, desfrute igualmente do prazer e delicadeza do teu relato (tradução de Delfim Leão).

${ }^{6}$ Satyricon 61: "Trimalquião voltou-se para Nicerote e disse: 'Você costumava ser mais amável no trato com os outros; não sei por que você hoje está calado, nem resmunga. Por favor, se você quer me ver feliz, conte aquilo que aconteceu a você"” (tradução nossa).
} 
são sempre lepidae - "graciosas, encantadoras, espirituosas" (Met. I 20; IV 27; IX 4; et passim). São histórias que provocam espanto (Sat. 63), assombro (Sat. 64), encorajamento (Sat. 88), risadas (Sat. 113).

Inicialmente as histórias breves inseridas ao longo da narrativa das Metamorphoseon são feitas sempre por outros personagens. O narrador homodiegético Lúcio divide a responsabilidade da narrativa com personagens secundários através da inserção de histórias fantásticas que cumprem o papel de ilustrar eventos da narrativa principal, ou mesmo de antecipar eventos que serão vivenciados pelo protagonista. Grande parte desses personagens secundários é introduzida basicamente, quase que exclusivamente, para contar sua história. $O$ fato é que o único personagem permanente na narrativa é o protagonista, ainda que ora sob aspecto humano, ora sob aspecto asinino.

À medida que a narrativa avança, o próprio protagonista passa a assumir também a função de inserir histórias - basta que ele queira.

Ibi coeptum facinus oppido memorabile narrare cupio. ${ }^{7}$

(...) hospitio proxumi stabuli recepti cognoscimus lepidam de adulterio cuiusdam pauperis fabulam, quam uos etiam cognoscatis uolo. ${ }^{8}$

Fabulam denique bonam prae ceteris, suaue comptam ad auris uestras adferre decreui, et en occipio.

A estratégia narrativa utilizada é similar àquela que discutimos para o Satyricon, ao longo das Metamorphoseon são inseridas numerosas histórias curtas de conteúdo fantástico, erótico, real de matiz dramático, que mantêm estreita relação com o relato da metamorfose do protagonista em asno. O fato é que são criadas dezenas de núcleos narrativos que, ao mesmo tempo em que desviam a atenção do leitor do cerne da narrativa, mantêm estreita relação com a mesma: são episódios que comentam a narrativa principal, antecipam acontecimentos, apresentam outra versão

\footnotetext{
${ }^{7}$ Metamorphoseon VIII 22, 1: Nessa localidade, tinha sido cometido um crime absolutamente digno de memória e que eu desejaria relatar (tradução de Delfim Leão).

${ }^{8}$ Metamorphoseon IX 4, 4: Ficámos alojados no albergue mais próximo, onde nos deram a conhecer a divertida história que eu gostaria de lhes contar: diz respeito ao adultério de que um pobre homem fora vítima (tradução de Delfim Leão).

${ }^{9}$ Metamorphoseon IX 14, 1: Por conseguinte, decidi presentear os vossos ouvidos com uma história, a melhor entre as melhores, agradável e graciosa, que agora mesmo vou iniciar (tradução de Delfim Leão).
} 
para os fatos. São eventos vividos pelo protagonista $\mathrm{x}$ eventos narrados ao protagonista $\mathrm{x}$ eventos narrados pelo protagonista.

À parte os episódios de cunho erótico vividos pelo próprio protagonista - aventuras de Lúcio com a escrava Fótis (II 7-10; 16-17) e aventuras amorosas do burro com uma matrona pollens et opulens (X 19-22) - as histórias inseridas apresentam relatos de experiências das quais o burro fora ora testemunha ocular, ora testemunha "auricular". Assim, Lúcio, um burro, ele mesmo um contador de histórias, preocupa-se em demonstrar sua habilidade como "contador de histórias", através de um certo refinamento das técnicas narrativas de que lança mão, como, por exemplo, quando, ao narrar o adultério de que seu atual dono estava sendo vítima (Met. IX 14-28), acrescenta à narrativa mais dois outros adultérios (Met. IX 17-21; Met. IX 24-25). Outra preocupação recorrente e manifesta do animal é com a verossimilhança da narrativa, como se pode comprovar pelos passos selecionados e destacados a seguir, apesar do evidente tratamento espetacular do tema da magia e da sedução:

Sed tibi prius deierabo solem istum omniuidentem deum me uera comperta memorare. ${ }^{10}$

Haec ad istum modum gesta compluribus mutuo sermocinantibus cognoui. Quibus autem uerbis accusator urserit, quibus rebus diluerit reus ac prorsus orationes altercationesque neque ipse absens apud praesepium scire neque ad uos, quae ignoraui, possim enuntiare, sed quae plane comperi, ad istas litteras proferam. ${ }^{11}$

As histórias pornográficas, sensacionalistas, misteriosas surgem no curso da narrativa de maneira fortuita, aparentemente sem motivo. Essa estratégia narrativa remonta à tradição, já desde Heródoto, ${ }^{12}$ de apresentar relatos de experiências e aventuras, próprias ou alheias, em lugares exóticos, um misto de relato historiográfico e literatura de viagem. ${ }^{13}$

\footnotetext{
${ }^{10}$ Metamorphoseon I 5, 1: Contudo, antes de mais, juro-te perante este Sol omnividente que contarei apenas factos verídicos e comprovados (tradução de Delfim Leão).

${ }^{11}$ Metamorphoseon X7, 3: Que foi esse o procedimento adotado, soube-o eu a partir das numerosas conversas ouvidas a propósito deste assunto. No respeitante, porém, às palavras usadas pela acusação durante o requisitório ou aos argumentos utilizados pelo réu na refutação, bem como em relação aos discursos e réplicas proferidos, nada conheço, pois encontrava-me no estábulo e portanto ausente do local. Em consequência, não thes posso apresentar pormenores que ignoro, mas aquilo sobre o qual tiver informação segura, vou expô-lo neste relato escrito (tradução de Delfim Leão).

${ }^{12}$ Cf. Verae historiae, de Luciano, que são uma paródia de obras do gênero, e as perdidas Babylonikae, de Iâmbulo.
} 


\section{Considerações finais}

O estudo das narrativas ficcionais, com princípio, meio e fim, inseridas na narrativa principal de ficção em prosa das obras Satyricon, de Petrônio, e Metamorphoseon, de Apuleio, permite delinear o modus narrandi e a função que assumem na obra: são histórias curtas que funcionam como elementos marcadores de tempo, espaço e/ ou drama psicológico dentro da narrativa principal. Mas, mais do que isso, são histórias fantásticas, que se apresentam ao leitor por meio de uma complexidade de técnicas narrativas, estratégias sofisticadas de composição e uma multiplicidade de perspectivas que têm envolvido leitores há séculos.

\section{Referências}

ANDERSON, G. The novella in Petronius. In: HOFMAN, H. (Org.). Latin fiction. The novel in context. London/ New York: Routledge, 2004.

APULEIO. O burro de ouro. Introdução, tradução do latim e notas de Delfim Leão. Lisboa: Livros Cotovia, 2007.

CONTE, G. B. The hidden author. An interpretation of Petronius's "Satyricon". Bekerley/ Los Angeles/ London: University of California Press, 1996.

de OLIVEIRA, F.; FEDELI, P.; LEÃO, D. (Org.). O romance antigo. Origens de um gênero literário. Coimbra: Imprensa de Coimbra Ltda., 2005.

OVIDE. L'art d'aimer. Texte établi et traduit par Henri Bornecque. Paris: Les Belles Lettres, 1929.

GENETTE, G. Nouveau discours du récit. Paris: Éditions du Seuil, 1983.

HARRISON, S. J. The Milesian tales and the Roman novel. In: HOFMANN, H.; ZIMMERMAN, M. (Org.). Groningen Colloquia on the Novel. Groningen: Egbert Forsten, 1998. Vol. IX, p. 61-73.

. Tristia; Ex Ponto. English translations by G. P. Gould and A. L. Wheeler. Cambridge, Mass./ London: Harvard University Press, 1924.

PETRÔNIO. Satyricon. Edição bilíngue, tradução e posfácio de Sandra Maria G. B. Bianchet. Belo Horizonte: Editora Crisálida, 2004.

SHUMATE, N. Apuleius' “Metamorphoses": the inserted tales. In: HOFMANN, H. (Org.). Latin fiction. The Latin novel in context. London/ New York: Routledge, 2004.

${ }^{13}$ Cf. Harrison, op. cit. p. 61-73. 